\title{
Modeling of Losses Due to Inter-Laminar Short-Circuit Currents in Lamination Stacks
}

\author{
Sahas Bikram Shah (Doctoral student, Aalto University), Paavo Rasilo (Researcher, Aalto University), \\ Anouar Belahcen (Professor, Aalto University), Antero Arkkio (Professor, Aalto University)
}

\begin{abstract}
The cores of electrical machines are generally punched and laminated to reduce the eddy current losses. These manufacturing processes such as punching and cutting deform the electrical sheets and deteriorate its magnetic properties. Burrs are formed due to plastic deformation of electrical sheets. Burr formed due to punching on the edges of laminated sheets impairs the insulation of adjacent sheet and make random galvanic contacts during the pressing of stacked sheets. The effect of circulating current occurs if the burrs occur on the opposite edges of the stacks of laminated sheets and incase of bolted or wielded sheets, induced current return through it. This induced current causes the additional losses in electrical machine. The existence of surface current on the boundary between two insulated regions causes discontinuity of tangential component of magnetic field. Hence, based on this principle, the boundary layer model was developed to study the additional losses due to galvanic contacts formed by burred edges. The boundary layer model was then coupled with 2-D finite element vector potential formulation and compared with fine mesh layer model. Fine mesh layer model consists of finely space discretized 950028 second order triangular elements. The losses were computed from two models and were obtained similar at $50 \mathrm{~Hz}$. The developed boundary layer model can be further used in electrical machines to study additional losses due to galvanic contacts at the edges of stator cores.
\end{abstract}

Keywords - Air gaps, eddy currents, finite element analysis, permeability.

\section{INTRODUCTION}

Electrical steel sheets are the indispensable constituent in the construction of cores of electromagnetic devices. Sheets are rolled to their given thickness, and laminated to minimize the eddy current loss. Later, they are cut or punched into desired shape for electromagnetic device. Sheets are laminated or coated before they are cut or punched to ease the punching process and also to prevent the damage of cutting tools and sheet itself [1]. Punching and cutting induces internal mechanical stresses which deforms the sheets and deteriorates their magnetic properties. The behavior of the magnetic properties and iron loss under such stress is studied in [2] where the hysteresis loss was observed due to change in permeability. It was observed in [3] that an annealing process reduces iron losses by $50 \%$ and produces a factor 3 change in permeability of test samples of laminated sheets. However, the cores of the electrical machines and transformers are not perfectly insulated from each other. The laminated sheets of electrical machines are subjected to many foreign particles during assembly and make galvanic contact between interlaminar sheets and makes thin conducting layer. However, manufacturing process such as punching also introduces burrs at the edges of electrical sheets and makes conducting layer and causes additional losses. The effect of punching has been widely researched in the scientific community. According to Schmidt [4], when cutting by punching, stress region can be from $0.35 \mathrm{~mm}$ up to $10 \mathrm{~mm}$ [5] from the cut edge and the deformed area can extend for about $0.3 \mathrm{~mm}$ due to plastic deformation [6]. It is studied that burr size of commercial material is less than $0.02 \mathrm{~mm}$ high in $0.28 \mathrm{~mm}$ thick sheet [7]. However, engineering society has agreed upon the average affected cut edge, having a width equal to or larger than the thickness of the lamination [8] and the ISO 13715 standard defines the edge of a work piece as burred if it has an overhang greater than zero [9].

\section{II.EFFECTS OF BURRS ON LAMINATED SHEETS}

A burr formed during punching of sheets has a strong impact on interlayer short circuits as well as on the cut edge properties. Burr formation occurs due to shearing during the separation of the metal by two blades. The series of the events occur when the moving blade gets in contact to the sheet and rolls over until reaching the fracture shear stress of the sheet [10], [11]. As the load continues to increase it initiates a crack which produces the rapid breakthrough involving a ductile fracture and formation of a burr as shown in Fig. 1 [12]. However, there are many de-burring techniques such as using electrochemical machining, abrasive flow machining or high pressure water jet but no single de-burring operation can accomplish 'burr free' conditions without having side effects [13].

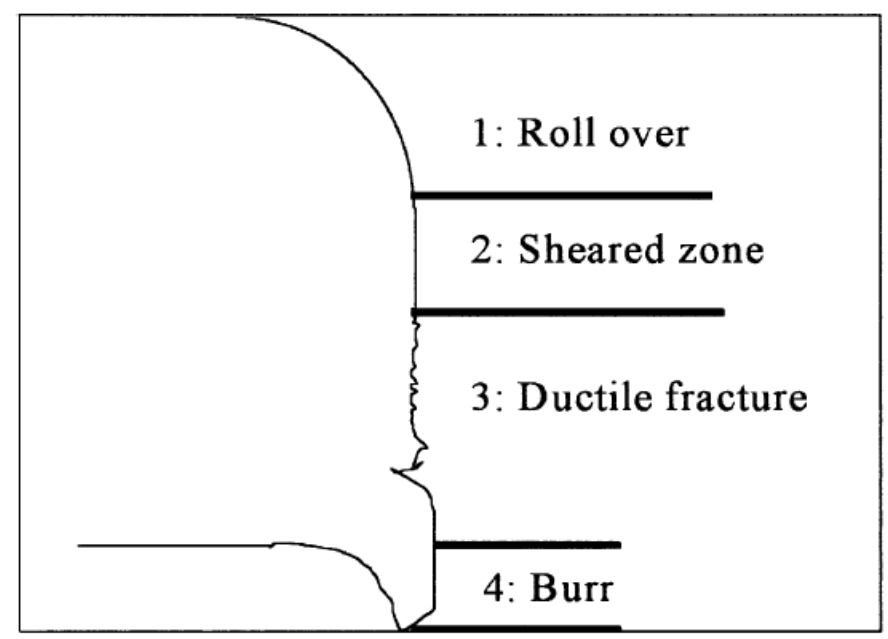

Fig. 1. Burr formation. 
Burrs formed at the edges of laminated sheet impair the insulation of adjacent sheet and make random galvanic contacts during pressing of stacked sheets. The effect of circulating eddy current occurs if burrs occur on opposite edges of the laminations and in case of bolted or welded sheets, induced current returns through these paths. These additional paths increase the loss and it is important to model such phenomena in order to identify the parameters which can minimize these effects. The effect of punching on magnetic properties is studied in [14] and [15] where the increment of hysteresis loss is up to $20-40 \%$ compared to guillotine cut and in [16] magneto-mechanical coupled FEM was proposed to model the effect. There are also few studies done regarding the modeling of inter-laminar short circuit losses using artificial burr contacts in [7], [17], [18], [19] and [20] where effect on permeability due to punching is assumed constant and randomness of burr contacts is not completely addressed. In [7] the experimental studies were done to measure the losses due to burr contacts. They drilled the laminated sheets to have the controllable artificial contacts. The contacts were varied by inserting conducting pins. They measured the loss on temperature rise principle. Temperatures were measured by using microprocessor controlled thermistor bridge. They concluded the increase of the loss due to burr contacts was up to $5 \%$ of total loss. There are also analytical studies done in [21], [22], [23], [24], [25] and [26] to model thin conducting layers using finite element method. However, the conducting layers formed by burrs within the stacks are uncertain, since they are formed by a stochastic process which depends on a large number of parameters, such as the age of punching die, stacking pressure, short circuit's geometry, thickness of the insulating layer and the number of sheets [27], [28].

The conducting layer formed by the burred edges can be modeled with finite element method with a very fine mesh layer and usually adaptive mesh is used but the fine mesh layer may consist of degenerated element or very high number of elements. The degenerated elements may lead to the system of ill conditioned matrix and hence the alternative method of modeling the thin conducting layer is required.

\section{Mathematical Modeling AND Methods}

\section{A. Thin Boundary Layer Formulation}

Burr formed at the edges of electrical sheets deteriorates the insulation and makes galvanic contacts. The surface current on the contact edges of a laminated sheet causes the discontinuity of the tangential component of the magnetic field [29]. It can be written as

$$
\mathbf{n} \times\left(\mathbf{H}_{1}-\mathbf{H}_{2}\right)=\int_{0}^{h} \mathbf{J} d x .
$$

It is assumed that the laminated sheets are parallel to the xy plane and the current density $\mathbf{J}$ is perpendicular to the plane and assumed constant in thin conducting layer. Under quasistatic approximation, the current density of a slab shown in Fig. 2 is given by $\mathbf{J}=\sigma \mathbf{E}$.

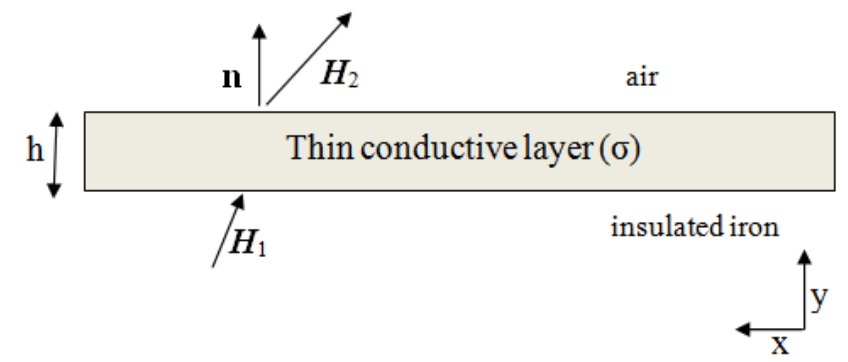

Fig. 2. Thin slab.

The current density is integrated along the conducting layer and surface current in terms of vector potential $\mathbf{A}=A_{z} \mathbf{k}$ is given by (1) where $\boldsymbol{v}_{1}, \boldsymbol{v}_{2}$ are the reluctivities of iron and air respectively.

$$
\mathbf{n} \times\left(\mathbf{H}_{1}-\mathbf{H}_{2}\right)=-\sigma h \frac{\partial \mathbf{A}}{\partial t} .
$$

The magnetic field can be expressed in terms of magnetic flux density using the material equation as

$$
\mathbf{n} \times\left(v_{1} \nabla \times \mathbf{A}-v_{2} \nabla \times \mathbf{A}\right)=-\sigma h \frac{\partial \mathbf{A}}{\partial t} .
$$

The magnetic vector potential $\mathbf{A}$ in $2 \mathrm{D}$ is in $\mathrm{z}$ direction and its gradient is written as in (7). Normal component can be decomposed in the two dimensional plane by writing as $\mathbf{n}=n_{\mathrm{x}} \mathbf{i}+n_{\mathrm{y}} \mathbf{j}$. Cross product of the vectors in (3) can be written as

$$
\begin{gathered}
{\left[\begin{array}{ccc}
\mathbf{i} & \mathbf{j} & \mathbf{k} \\
n_{x} & n_{y} & 0 \\
v_{1} \frac{\partial A_{z}}{\partial y} & -v_{1} \frac{\partial A_{z}}{\partial x} & 0
\end{array}\right]-\left[\begin{array}{ccc}
\mathbf{i} & \mathbf{j} & \mathbf{k} \\
n_{x} & n_{y} & 0 \\
v_{2} \frac{\partial A_{z}}{\partial y} & -v_{2} \frac{\partial A_{z}}{\partial x} & 0
\end{array}\right]=-\sigma h \frac{\partial A_{z}}{\partial t} \mathbf{k}(4)} \\
\left.-n_{\mathbf{x}} v_{1} \frac{\partial A_{z}}{\partial x}-n_{\mathbf{y}} v_{1} \frac{\partial A_{z}}{\partial y}\right] \mathbf{k}-\left[-n_{\mathrm{x}} v_{2} \frac{\partial A_{z}}{\partial x}-n_{\mathbf{y}} v_{2} \frac{\partial A_{z}}{\partial y}\right] \mathbf{k}=-\sigma \frac{\partial A_{z}}{\partial t} \mathbf{k} .
\end{gathered}
$$

The surface current in terms of magnetic vector potential can be written as

$$
v_{1} \nabla A_{z} \cdot \mathbf{n}-v_{2} \nabla A_{z} \cdot \mathbf{n}=\sigma h \frac{\partial A_{z}}{\partial t} .
$$

The magnetic flux density is the curl of magnetic vector potential and in two dimensional study, it can be expressed as

$$
\mathbf{B}=\left[\begin{array}{ll}
\mathbf{i} & \mathbf{j}
\end{array}\right]\left[\begin{array}{c}
\frac{\partial A_{z}}{\partial y} \\
-\frac{\partial A_{z}}{\partial x}
\end{array}\right] .
$$

The gradient of $A_{z}$ can be expressed as

$$
\nabla A_{z}=\left[\begin{array}{ll}
\mathbf{i} & \mathbf{j}
\end{array}\right]\left[\begin{array}{c}
\frac{\partial A_{z}}{\partial x} \\
\frac{\partial A_{z}}{\partial y}
\end{array}\right]
$$


The magnetic flux density can be expressed in terms of gradient of magnetic vector potential with the introduction of matrix term. It can be written as

$$
\mathbf{B}=\left[\begin{array}{cc}
0 & 1 \\
-1 & 0
\end{array}\right] \nabla A_{z} .
$$

The material equation $\mathbf{B}=\mu \mathbf{H}$ is used. Equation (8) is substituted in material equation. The introduced matrix is inversed and $\boldsymbol{v} \boldsymbol{\nabla} A_{\mathrm{z}}$ is expressed in terms of $\mathrm{H}$ as in (9).

The expression $\boldsymbol{v} \boldsymbol{\nabla} A_{\mathrm{z}} \cdot \mathbf{n}$ can be graphically represented as the tangential component of magnetic field in Fig. 3.

$$
v \nabla A_{z}=\left[\begin{array}{cc}
0 & -1 \\
1 & 0
\end{array}\right] \mathbf{H}
$$

\section{B. Coupling of Boundary Layer Model into 2D Model}

Maxwell equations in terms of magnetic vector potential is solved in two non conducting regions using Green's theorem and weighted residual method. The weight function vanishes along the Dirichlet boundaries $\Gamma_{\text {dir }}$ and $\Gamma_{\text {dair }}$. The presence of surface current along the boundaries $\Gamma_{\mathrm{ia}}$ and $\Gamma_{\mathrm{ai}}$ causes the discontinuity of tangential magnetic field. Hence, the coupling of the boundary layer model into 2D finite element of two insulated iron and air region as shown in Fig. 4 is given by

$$
\begin{aligned}
R= & \int_{\Omega_{i r}} v_{1} \nabla A_{z} \cdot \nabla w d \Omega+\int_{\Omega_{\text {air }}} v_{2} \nabla A_{z} \cdot \nabla w d \Omega \\
& -\int_{\Gamma_{i a}} w \sigma h \frac{\partial A_{z}}{\partial t}=0 .
\end{aligned}
$$

Equation (10) was space discretized by replacing weight function $w$ with shape functions of active nodes. The coupling of boundary layer model to $2 \mathrm{D}$ finite element method results in the system of equations

$$
S \mathrm{a}+\boldsymbol{T} \dot{\mathrm{a}}=0
$$

where,

$$
\begin{aligned}
\boldsymbol{S}_{i j}= & \int_{\Omega} v \nabla N_{i} \cdot \nabla N_{j} d \Omega, \\
& i, j=1, . ., 3 \\
\dot{\mathrm{a}}= & \frac{\partial \mathbf{a}}{\partial t} \\
\boldsymbol{T}_{i j}= & \int_{i a} \sigma h N_{i} N_{j}, \\
& i, j=1, . ., 3 .
\end{aligned}
$$

The system of equations is solved as $\boldsymbol{\nu}=\boldsymbol{v}_{2}$ (constant for air) and $\boldsymbol{v}=\boldsymbol{v}_{1}$ (linear insulated iron region). $\boldsymbol{S}$ is the stiffness matrix and $\boldsymbol{T}$ is the damping matrix which accounts for time dependent terms. The coupling of the boundary layer model in existing system of equations results in an additional term in time dependent matrices. It is important to know that the additional term in $T_{\mathrm{ij}}$ is the line integration along the material boundaries and shape functions $N_{\mathrm{i}}$ and $N_{\mathrm{j}}$ corresponds to only nodes that belong to the material boundaries.

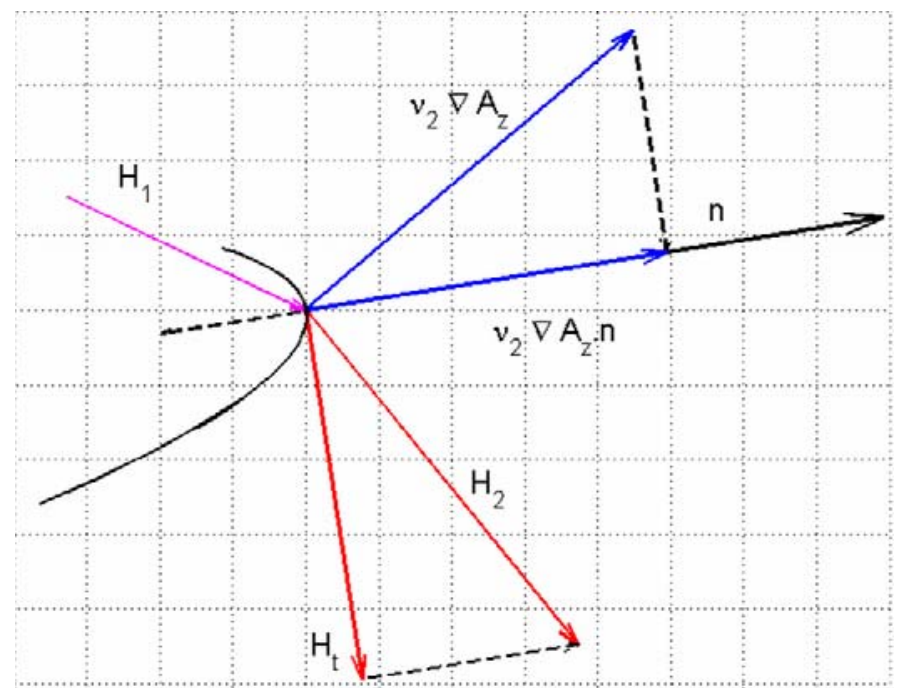

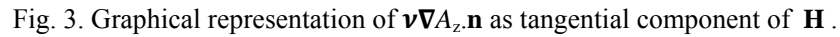

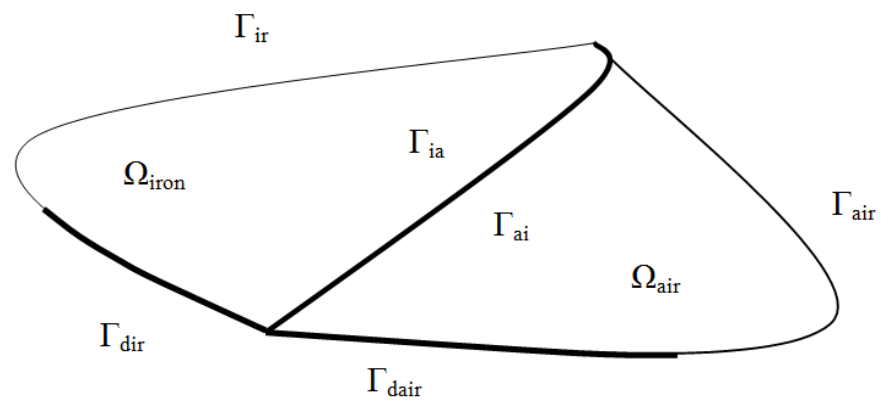

Fig. 4. Insulated iron and air region.

\section{RESULtS}

The derived mathematical boundary layer model is given by (1). It is compared with fine mesh model in electrical UI sheets in finite element software COMSOL. In fine mesh layer model, thin conducting region is finely space discretized. It consisted of 950028 quadratic triangular elements as shown in Fig. 5.

The two models are compared with same mesh in the frequency domain, changing frequency from $50 \mathrm{~Hz}$ to $150 \mathrm{~Hz}$ and parametrizing thickness of conducting layer from 0.05 $\mathrm{mm}$ to $0.2 \mathrm{~mm}$. The air gap flux density of two different models, obtained from COMSOL, was compared. The difference in the air gap flux density between the $U$ and I sheet in different frequencies and conducting width can be seen in Fig. 6 and Fig. 7.

The galvanic contacts along the edges of UI sheets can be modeled by assigning constant conductivity of iron at the edges. The losses due to galvanic contacts were computed from both models. The losses obtained from two models behave very closely at $50 \mathrm{~Hz}$ and $100 \mathrm{~Hz}$. 

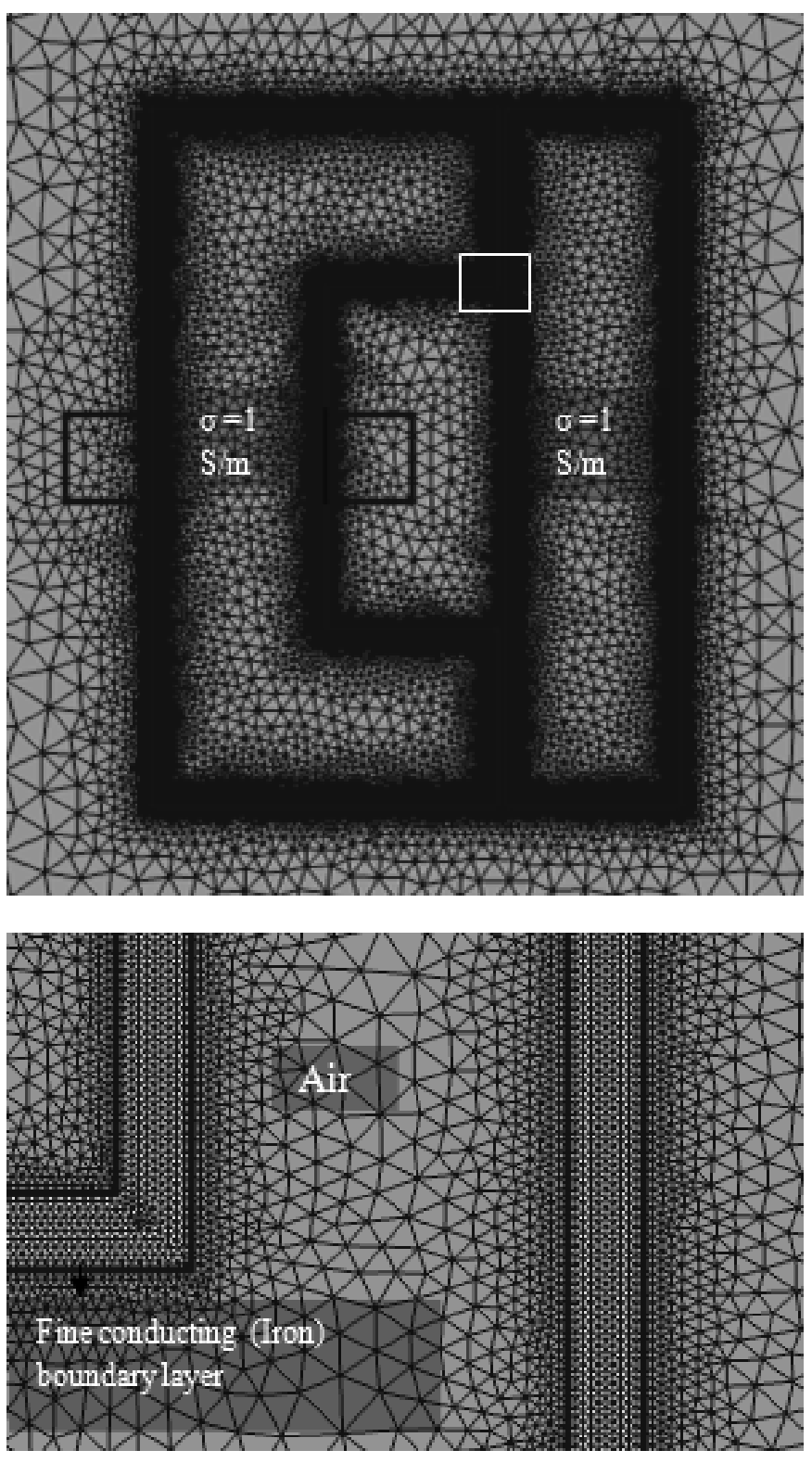

Fig. 5. Fine mesh layer of UI model.

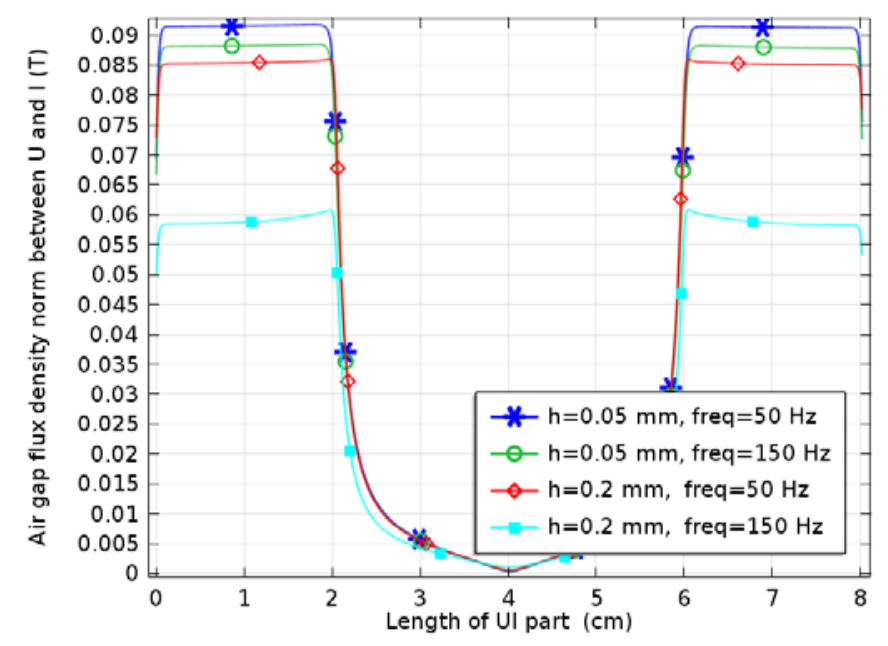

Fig. 6. Air gap flux density of boundary layer model.
The losses increased with frequency increasing and this behaviour can be seen in Fig. 8. However, at high frequency and at conducting width of $0.15 \mathrm{~mm}$, the losses start to decrease, probably because of shielding effect. In fine layer model, at high frequency the flux cannot penetrate near the skin depth and hence the losses start to decrease. However, boundary layer model is less affected by skin depth. It can be seen from Fig. 8 that the two models behave closely in loss computation.

The developed boundary layer model has a wide application. It can also be used to model conducting layer that is used in high speed permanent magnet machines to lower eddy current loss and to damp mechanical oscillations and screening of an inverse field [30]. However, the process of burr formation and the contacts of sheets on the edges of laminated sheet is random in nature and hence requires stochastic approach to the solution. Uncertainities in magnetic vector potential can be quantified as in [31]. The random distribution of conductivity and burr width can be obtained by measuring the resistivity along the edges of numerous samples of sheets as a function of stacking pressure [32]. Thus, obtained experimental data can be validated using an appropriate stochastic model with the aid of statistical tools.

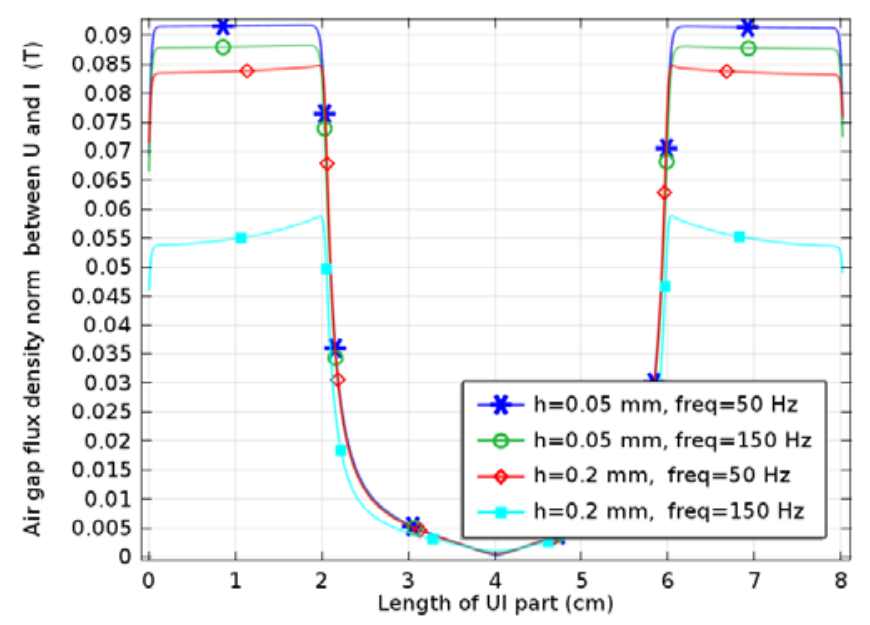

Fig. 7. Air gap flux density of fine layer model.

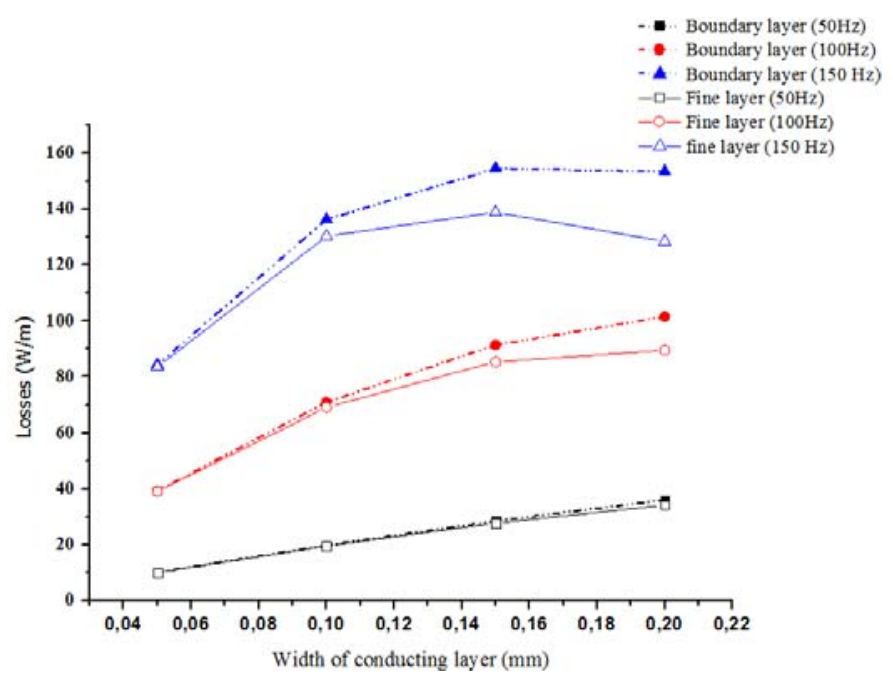

Fig. 8. Comparison of the two models. 


\section{V.CONCLUSION}

In conclusion, the boundary layer model can compute the loss similar to fine mesh layer model at $50 \mathrm{~Hz}$ and at burr width less than $0.2 \mathrm{~mm}$. However, boundary layer model predicts more losses than fine mesh model at $150 \mathrm{~Hz}$ frequency and $0.2 \mathrm{~mm}$ burr width. The maximum difference between the losses computed from these two model was 19 $\%$. The boundary layer model provides the mesh free solution at the thin conducting region. This model can be used to study the additional losses due to interlaminar galvanic contacts in $37 \mathrm{~kW}$ induction machine considering the random conductivity. This application will be presented in the future paper.

\section{ACKNOWLEDGMENT}

The authors would like to thank CLEEN / Future Combustion Engine Power Plants (FCEP) research programme for their financial support.

\section{REFERENCES}

[1] D. M. Lindenmo and A. Coombs, "Advantages, properties and types of coatings on non-oriented electrical steels," Journal of Magnetism and Magnetic Materials, Vol. 215-216, pp. 79-82, 2000.

[2] A. Kedous-Lebouc, B. Cornut, J. Perrier, P. Manfe and T. Chevalier, "Punching influence on magnetic properties of the stator teeth of an induction motor," Journal of Magnetism and Magnetic Materials, Vol. 254-255, pp. 124-126, 2003.

[3] A. Boglietti, A. Cavagnino, L. Ferraris and M. Lazzari, "The annealing influence onto the magnetic and energetic properties in soft magnetic material after punching process," IEEE Electric Machines and Drives Conference, 2003.

[4] K. Schmidt, "Influence of punching on the magentic properties of electric steel with $1 \%$ silicon," Journal of Magnetism and magnetic materials, vol. 2, no 1-3, pp. 136-150, December 1975.

[5] A. Moses, N. Derebasi, G. Loisos and A. Schoppa, "Aspects of the cut edge effect stress on the power loss and flux density distribution in electrical steel sheets," Journal of Magnetism and Magnetic Materials, Vol.215-216, pp. 690-692, 2000.

[6] M. Emura, F. Landgraf, W. Ross and J. Barreta, "The influence of cutting technique on the magnetic properties of steel," Journal of Magnetism and Magnetic materials, Vol.254-255, pp. 358-360, 2003.

[7] A. Moses and M. Aimoniotis, "Effects of Artifical Edge burrs on the properties of a Model transformer core," Physica Scripta, vol. 39, pp. 391-393, 1989.

[8] P. Beckley, Electrical steels for rotating machines, The Institution of Engineering and Technology, London, 2002.

[9] Technical drawings-Edges of undefined shape Vocabulary and indications, International Standard ISO 13715:2000.

[10] S. L. Ko and A. D. Dornfeld, "A study on burr formation mechansim," Transaction of the ASME Journal of Engineering Material and Technology, vol. 113, no 1, pp. 75-87, 1991.

[11] L. K. Gillespie and P. T. Blotter, "The formation and properties of machining burrs," Journal of Engineering for Industry, vol. 98, no 1, pp. 66-74, 1976.

[12] P. Baudouin, M. Wulf, L. Kestens and Y. Houbaert, "The effect of the guillotine clearance on the magnetic properties of electrical steels," Journal of Magnetism and Magnetic Materials, vol. 256, pp. 32-40, 2003.

[13] J. Aurich, D. Dornfeld, P. Arrazola, V. Franke, L. Leitz and S. Min, "Burrs-analysis, control and removal," CIRP Annuals-Manufacturing technology, vol. 58, no 2, pp. 519-542, 2009.

[14] A. Boglietti, A. Cavagnino, M. Lazzari and M. Pastorelli, "Effect of punch process on the magnetic and energetic properties of soft magnetic material," Electric machines and drives conference,IEMDC 2001, pp. 396-399, 2001.

[15] M. W. Arshad, T. Ryckebush, F. Magnussen, H. Lendenmann, J. Soulard, B. Eriksson and B. Malmros, "Incorporating lamination processing and component manufacturing in electrical machine tools," Industry Applications Conference, 2007. 42nd IAS Annual meeting, 2007.

[16] F. Ossart, E. Hug, O. Hubert, C. Buvat and R. Billardon, "Effect of punching on electrical steels: Experimental and numerical," IEEE Transactions on Magnetics, vol. 36, no 5, pp. 3137-3140, 2000.

[17] R. Mazurek, H. Hamzehbahmani, A. J. Moses, P. I. Anderson, F. J. Anayi and T. Belgrand, "Effect of Artificial Burrs on Local Power Loss in a Three-Phase Transformer Core," IEEE Transactions on Magnetics, vol. 48, pp. $1653-1656,2012$.

[18] R. Mazurek, P. Marketos, A. Moses and N. J. Vincent, "Effect of artifical burrs on the total power loss of a three phase transformer core," IEEE transaction on magnetics, vol. 46, pp. 638-641, 2010.

[19] R. Jean-Yves, V. Emmanuel, H. Thomas, B. Abdelkader and D. JeanPierre, "Electromagnetic modelling of short circuited coreplates".

[20] S. B. Lee, G. Kliman, M. Shah, W. Mall, N. Nair and R. Lusted, "Advanced technique for detecting interlaminar stator core faults in large electric machines," IEEE transaction on Industry application, vol. 41, pp. 1185-1193, 2005.

[21] H. Igarashi, A. Kost and T. Honma, "Impedance boundary condition for vector potentials on thin layers and its application to integral equations," The European Physical Journal Applied Physics, vol. 1, no 1, pp. 103109, 1998.

[22] C. Brebbia, Topics in Boundary Element research, Springer Verlag Berlin, 1989

[23] L. Krahenbuhl and D. Muller, "Thin layers in electrical engineering example of shell models in analysing eddy currents by boundary and finite element methods," IEEE transaction on Magnetics, vol. 29, pp. 1450-1455, 1993.

[24] C. Geuzaine, P. Dular and W. Legros, "Dual formulations for the modeling of thin electromagnetic shells using edfe elements," IEEE transactions on Magnetics, vol. 36, pp. 799-803, 2000.

[25] J. Gyselinck, R. Sabariego, P. Dular and C. Geuzaine, "Time domain finite element modeling of thin electromagnetic shells," IEEE transaction on Magnetics, vol. 44, pp. 742-745, 2008.

[26] R. Sabariego, C. Geuzaine, P. Dular and J. Gyselinck, "Non-linear time domain finite element modeling of thin electromagnetic shells," IEEE transaction on magnetics, vol. 45, pp. 976-979, 2009.

[27] C. A. Schulz, S. Duchesne, D. Roger and J. N. Vincent, "Capacitive short circuit detection in transformer core laminations," Journal of Magnetism and Magnetic Materials, vol. 320, no 20, pp. 911-914, 2008.

[28] G. Iaccarino, Uncertainty quantification in computation science, Department of Mechanical Engineering Stanford University, 2011.

[29] J. Luomi, Finite element methods for electrical machines, Goteborg: Chalmers University of Technology, Department of Electrical Machine and Power electronics, 1993.

[30] J. Van der veen, L. Offringa and A. Vandenput, "Minimising rotor losses in high speed high power permanent magnet synchronous generators with rectifier load," Electric Power Applications, IEEE Proceedings, vol. 144, pp. 331-337, 1997.

[31] K. Beddek, Y. L. Menach, S. Clenet and O. Moreau, "3-D Stochastic spectral finite element method in static electromagnetism using vector potential formulation," IEEE transaction om magnetics, vol. 47, no 5, pp. 1250-1252, 2011.

[32] E. D. Taylor, "The measurement of interlaminar resistance of varnish insulated silicon steel sheet for large electrical machines," Proceedings of IEE-part II : Power engineering, vol. 98, no 63, pp. 377-385, 1951. 


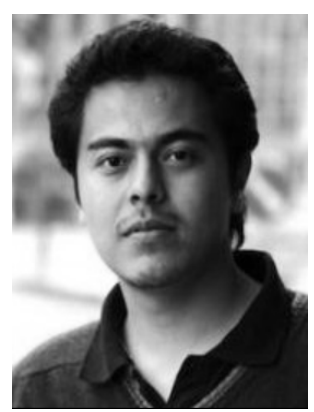

Sahas Bikram Shah was born in Kathmandu, Nepal in 1987. He received the B.Sc. degree in electrical and electronics engineering from Kathmandu University, Nepal in 2010 and the M.Sc. (Tech.) from Aalto University, Espoo, Finland in 2013. His main study includes numerical modeling in electrical machines and electromechanics.

$\mathrm{He}$ is currently a doctoral student at the Department of Electrical Engineering in Aalto University School of Electrical Engineering. His research includes numerical modeling of iron losses in electrical machines and stochastic analysis of additional losses in electric machines.

E-mail: sahas.bikram.shah@aalto.fi

Postal address: Aalto University, School of Science and Technology, Department of Electrical Engineering, P.O.Box 13000, FI-00076 Aalto, Finland.

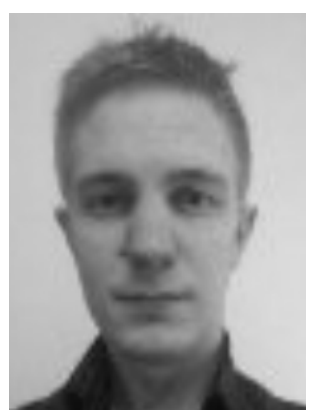

Paavo Rasilo was born in Äänekoski, Finland in 1983. He received his M.Sc. (Tech.) and D.Sc. (Tech.) degrees from Helsinki University of Technology (currently Aalto University) and Aalto University, Espoo, Finland in 2008 and 2012, respectively.

$\mathrm{He}$ is currently a post-doctoral researcher at the Department of Electrical Engineering in Aalto University School of Electrical Engineering. His research interests deal with numerical modeling of electrical machines as well as power losses and magnetomechanical effects in soft magnetic materials.

Postal address: Aalto University, School of Science and Technology, Department of Electrical Engineering, P.O.Box 13000, FI-00076 Aalto, Finland.

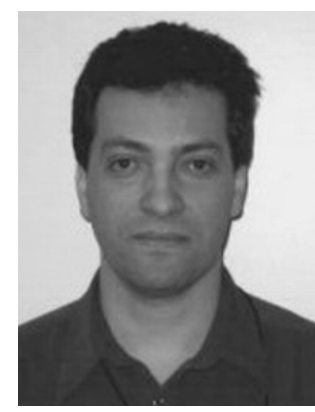

Anouar Belahcen was born in Morocco, in 1963. He received the B.Sc. degree in physics from the University Sidi Mohamed Ben Abdellah, Fes, Morocco, in 1988 and the M.Sc. (Tech.), LisTech, and Doctorate degrees from Helsinki University of Technorking as Professor in the field of coupled problems and material modeling at the Department of Electrical Engineering, Aalto University, Finland. Since 2011 he is Professor of electrical machines at Tallinn University of Technology, Estonia and in 2013 he became Professor at Aalto University. His research interests deal with the numerical modeling of electrical machines, especially magnetic material modeling, coupled magnetic and mechanical problems, magnetic forces, and magnetostriction.

Postal address: Aalto University, School of Science and Technology, Department of Electrical Engineering, P.O.Box 13000, FI-00076 Aalto, Finland.

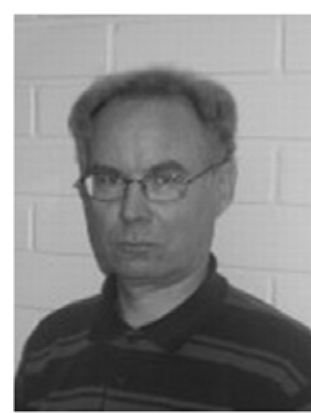

Antero Arkkio was born in Vehkalahti, Finland in 1955. He received his M.Sc. (Tech.) and D.Sc. (Tech.) degrees from Helsinki University of Technology in 1980 and 1988.

Currently he is a Professor of Electrical Engineering at Aalto University. His research interests deal with modeling, design, and measurement of electrical machines.

Postal address: Aalto University, School of Science and Technology, Department of Electrical Engineering, P.O.Box 13000, FI-00076 Aalto, Finland. 